\title{
Antegrade flexible intramedullary nailing through the greater trochanter in paediatric femur shaft fractures
}

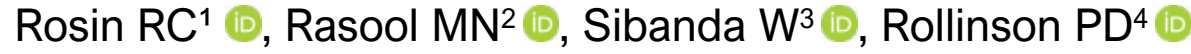 \\ 1 MBChB(UCT); Orthopaedic Registrar, Department of Orthopaedic Surgery, Nelson R Mandela School of Clinical Medicine, University of \\ KwaZulu-Natal, South Africa \\ $2 \mathrm{MBCH}, \mathrm{FCS}(\mathrm{SA}), \mathrm{PhD}$; Professor of Paediatric Orthopaedic Surgery, Nelson R Mandela School of Clinical Medicine, University of KwaZulu-Natal \\ 3 PhD Statistics (North-West University); Biostatistics Unit, School of Nursing and Public Health, College of Health Sciences, University of \\ KwaZulu-Natal, Durban, South Africa \\ 4 MBChB(Sheff), FRCS (Ed \& Eng); Chief Orthopaedic Specialist, Ngwelezana Hospital, Empangeni, KwaZulu-Natal, South Africa
}

Corresponding author: Dr Rainer Christian Rosin, 40 Halford Road, Musgrave, Durban, 4001; tel: 0725840361; email: rainerrosin@gmail.com

\begin{abstract}
Aims: To determine whether an antegrade approach, through the tip of the greater trochanter, in femoral shaft fractures in children, is safe, achieves adequate union and results in significant proximal femoral growth complications.

Patients and methods: The case records and radiographs of 23 paediatric patients aged 7 to 12 years with femur shaft fractures managed with stainless steel antegrade flexible nailing were reviewed retrospectively. Pre-operative radiographs were reviewed for fracture pattern, level and comminution. Post-operative radiographs were reviewed to assess for union, alignment, osteonecrosis of the femoral head and epiphysiodesis of the greater trochanter. Morphological changes of the proximal femur were assessed by comparing the neck shaft angle and articulo-trochanteric distance with the opposite hip. Case records were reviewed for post-operative complications, patient-reported complaints and leg length discrepancy. Clinical outcomes were assessed with the criteria established by Flynn.
\end{abstract}

Results: All patients achieved union, and none had evidence of osteonecrosis of the femoral head on follow-up. Three patients had malalignment and two patients had radiographic evidence of greater trochanteric epiphysiodesis. Two patients had morphological changes of the proximal femur, with one having an increased neck shaft angle and one an increased articulo-trochanteric distance. One patient had a leg length discrepancy of $2 \mathrm{~cm}$. Fifteen patients had excellent clinical outcomes, five had satisfactory outcomes and three had poor outcomes according the criteria established by Flynn.

Conclusion: Antegrade entry through the tip of the greater trochanter does not appear to compromise the blood supply to the femoral head or increase the risk of clinically significant morphological changes to the proximal femur. All patients achieved adequate union. Furthermore, antegrade insertion avoided skin problems and prominent nail complications around the knee seen with retrograde insertion.

Level of evidence: Level 4

Keywords: paediatric, femur shaft fractures, flexible intramedullary nails, antegrade

Citation: Rosin RC, Rasool MN, Sibanda W, Rollinson PD. Antegrade flexible intramedullary nailing through the greater trochanter in paediatric femur shaft fractures. SA Orthop J 2019;18(4):20-27. http://dx.doi.org/10.17159/2309-8309/2019/v18n4a2

Editor: Dr GB Firth, University of Witwatersrand, Johannesburg, South Africa

Received: April 2019

Accepted: July 2019

Published: November 2019

Copyright: ( 2019 Rosin RC. This is an open-access article distributed under the terms of the Creative Commons Attribution Licence, which permits unrestricted use, distribution and reproduction in any medium, provided the original author and source are credited.

Funding: This study received no funding.

Conflict of interest: All authors declare having no conflict of interest with regard to this study. 


\section{Introduction}

The incidence of femoral shaft fractures in South Africa is estimated to be 0.25 per 1000 children per year. ${ }^{1}$ The management of paediatric femoral shaft fractures includes both non-operative and operative options. ${ }^{2}$ Flexible intramedullary nails (FIN) are becoming increasingly popular in the $5-11$ year-old age group.

The standard approach for insertion of FIN is retrograde, with medial and lateral entry portals. This approach avoids the greater trochanteric epiphysis and vessels supplying the femoral head. Damage to these structures raises concerns regarding interruption to the blood supply of the femoral head, as well as growth disorders resulting from damage and subsequent epiphysiodesis of the greater trochanteric epiphysis.

Paediatric femoral shaft fractures have been managed with FIN since 1999 in the orthopaedic department of a regional hospital in KwaZulu-Natal. Being a resource-limited hospital at that time, the selection of the implant was greatly influenced by the cost. As a result, stainless steel flexible rods (Rush rods) were preferred over more expensive titanium elastic nails. The orthopaedic department was staffed by relatively junior medical officers and so an antegrade approach was adopted. This approach was considered to be easier as it had the same theatre setup and patient positioning as used for adult femoral antegrade nailing, which was done on a more regular basis. This approach also avoids the distal femoral epiphysis unlike the standard retrograde approach. Early experience revealed very few complications and it became the method of treatment for children from the age of 7 years.
The aim of this study was to determine whether an antegrade approach with rod insertion through the tip of the greater trochanter is safe, achieves adequate union, and whether this approach results in any significant proximal femoral complications.

\section{Materials and methods}

A retrospective study was done between June 2011 and June 2017 at a regional hospital in KwaZulu-Natal. A search of the operation slate database of the orthopaedic department for this period revealed 67 paediatric patients aged 7 years to 12 years with 67 femoral shaft fractures treated operatively.

Patients were admitted either directly or from one of 14 peripheral referring hospitals, servicing a population of 2.34 million people. The children were physiologically stabilised and were taken to theatre on the earliest available elective slate, aiming to get the fracture fixation performed within ten days of the date of injury. The patients were positioned supine on a traction table in a similar setup for antegrade nailing for an adult femur fracture but using a smaller perineal support (Figure 1a). A $1 \mathrm{~cm}$ stab incision was made proximal to the greater trochanter and carried down to the tip of the trochanter. A $4.5 \mathrm{~mm}$ Rush rod hand reamer was used to perforate the tip of the trochanter under fluoroscopic guidance, taking care to stay within the proximal femoral canal (Figure 1b). Two $3.2 \mathrm{~mm}$ Rush rods, the length of which were determined intraoperatively, were contoured with a distal bend forming a 'J-shape'. The first rod was advanced down to the fracture level. By rotating the rod and utilising the distal bend as well as manual manipulation,

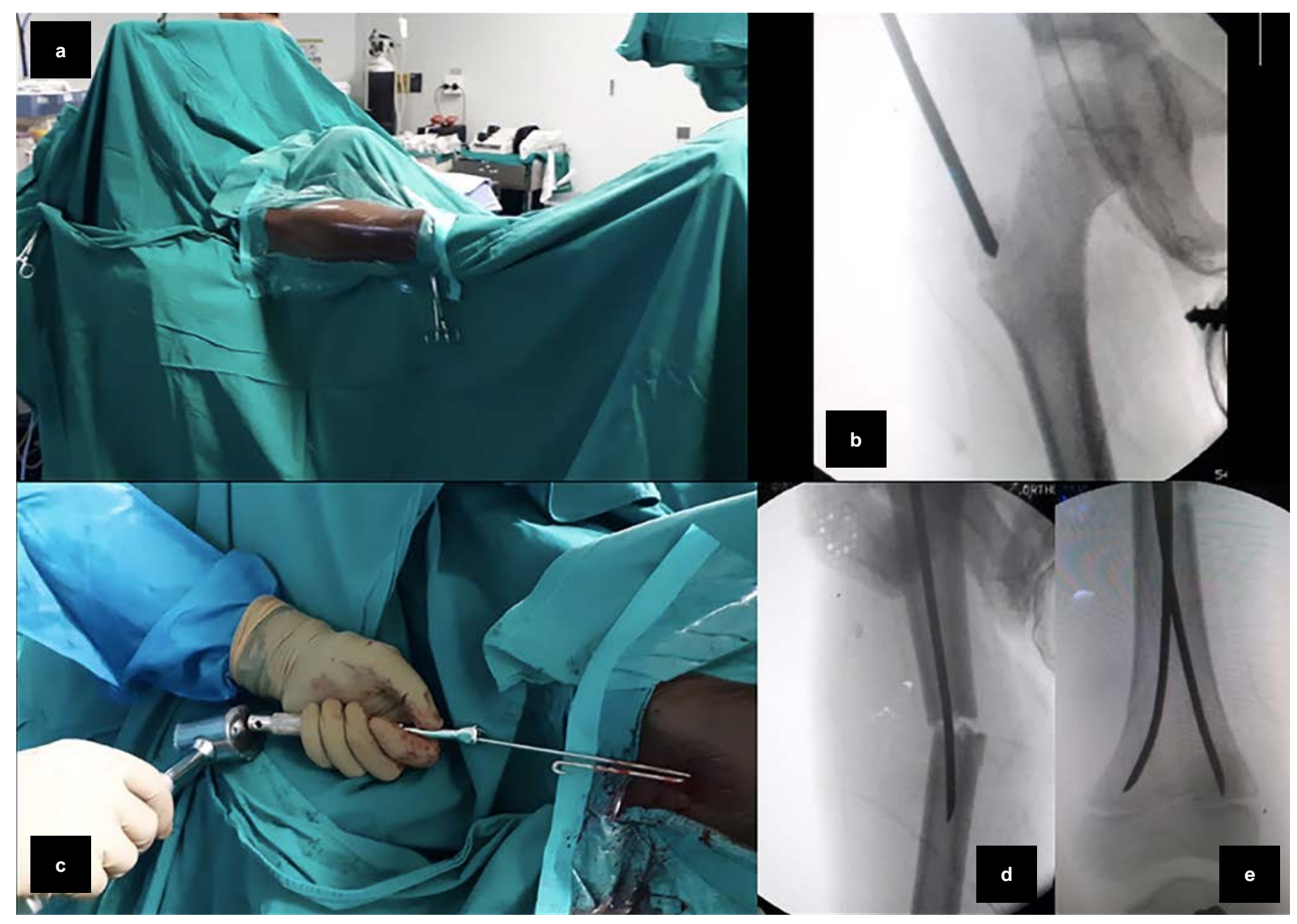

Figure 1. Intra-operative technique: a) Patient positioned supine on traction table; b) entry through tip of trochanter with a $4.5 \mathrm{~mm}$ hand reamer; c) passing first rod across fracture site after reduction; d) advancing rods with aid of mallet; e) final positioning of rods 


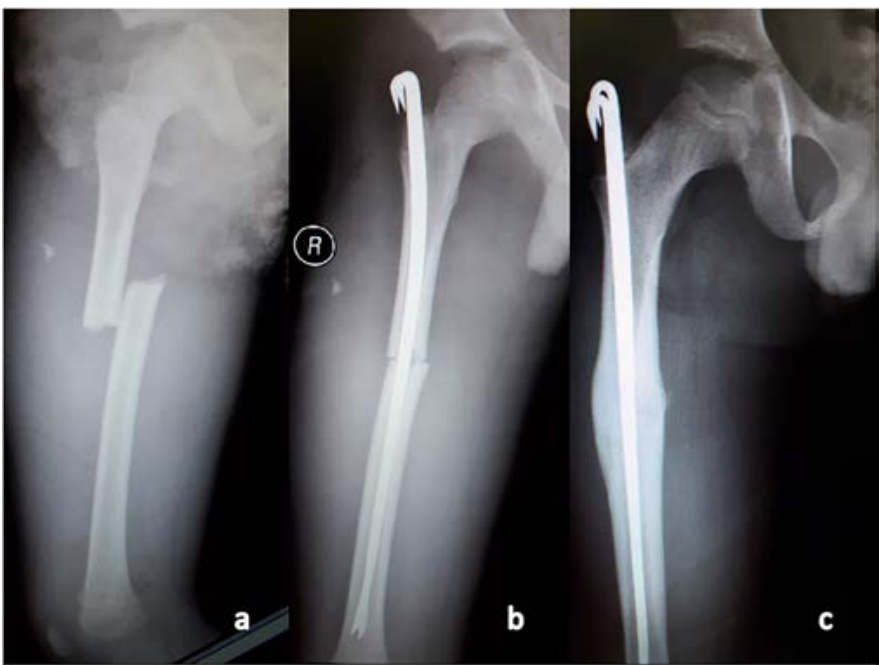

Figure 2. a) Pre-operative radiograph; b) immediate post-operative radiograph; and c) radiograph showing union after 6 months

fracture reduction was achieved, and the rod was passed into the distal segment (Figure 1c). The second rod was then introduced by carefully aligning the bent tip of the rod with the entry portal adjacent to the first rod, screening with AP and lateral views. Once correctly positioned, the rod was advanced using a rod introducer and mallet (Figure 1d). Once across the fracture site, both rods were advanced down the distal femoral canal with the ideal configuration being to splay the rods in the medial and lateral distal metaphyses to gain rotational control of the fracture (Figure 1e). The proximal ends of the Rush rods were left approximately $2 \mathrm{~cm}$ out of the tip of the greater trochanter to facilitate future removal.

Post-operatively, patients with stable fracture patterns (such as transverse short oblique fractures) were mobilised immediately with partial weight-bearing. Alternatively, if the fracture was classified as unstable, the patient was placed on skin traction for approximately 10 to 14 days to allow early callus formation to stabilise the fracture before allowing mobilisation on crutches. Figure 2 shows an example of a fracture fixed using the above technique preoperatively, immediately post-operatively and at union.

Data was obtained retrospectively from case records and radiographic analysis. Initial radiographs were assessed for fracture level, pattern and comminution according to the Winquist and Hansen classification. ${ }^{3}$ Follow-up radiographs were assessed for signs of femoral head osteonecrosis, neck shaft angle difference (NSAD), articulo-trochanteric distance difference (ATDD), union and alignment. The articulo-trochanteric distance was defined as the distance between two lines drawn perpendicular to the femoral anatomical axis. The first line is drawn through the tip of the greater trochanter and the second line tangential to the highest level of the femoral head (Figure 3). The ATDD measures the growth of the greater trochanter relative to the femoral head. An increase in ATDD indicates a relative undergrowth of the greater trochanter due to epihysiodesis. The normal articulo-trochanteric distance in children aged 5 to 13 years is $23 \mathrm{~mm}( \pm 4.5 \mathrm{~mm})$ and $16 \mathrm{~mm}$ $( \pm 3.6 \mathrm{~mm})$ in males and females respectively. ${ }^{4}$ In order to account for any differences in magnification of the radiographs, the ATDD was reported as an index of the affected side divided by the unaffected side. The ATDD was considered abnormal if it was greater than $10 \mathrm{~mm} \cdot{ }^{5} \mathrm{~A}$ normal ATDD index range was therefore calculated with the following formula, '(normal +10$) /$ normal' for the upper range and '(normal - 10)/normal' for the lower range. Thus, an ATDD index range of 0.57 to 1.44 for males and 0.38 to 1.68 for females was considered normal. Leg length was assessed clinically using a measuring tape. Clinical outcomes were assessed according to criteria proposed by Flynn et al. ${ }^{6}$

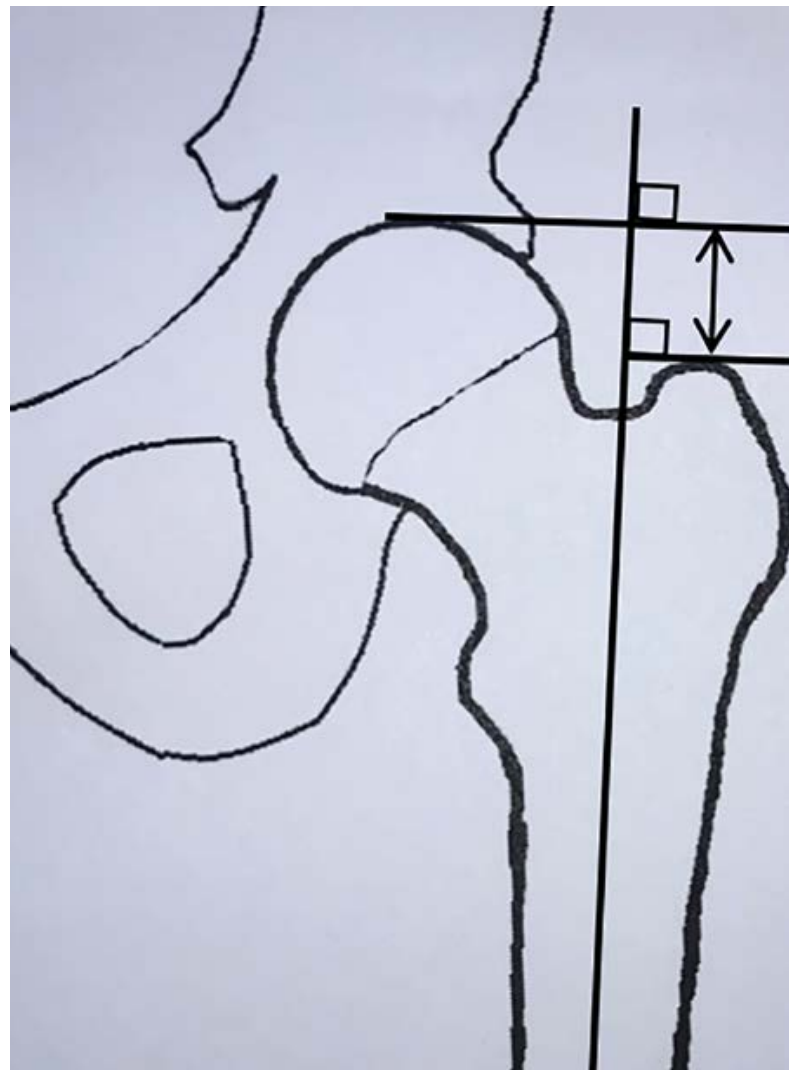

Figure 3. Articulo-trochanteric distance

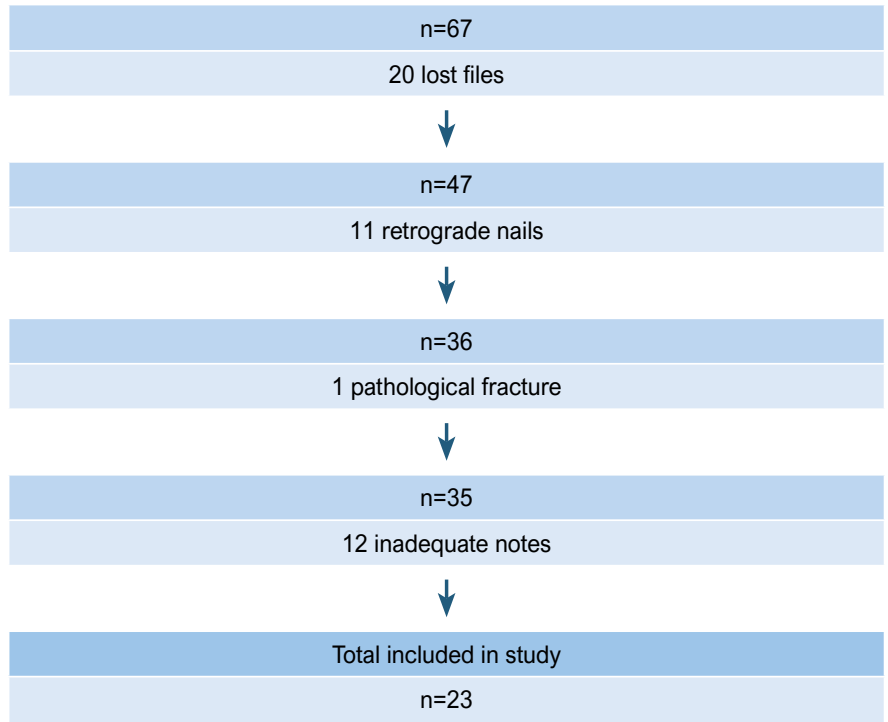

Figure 4. Exclusions

Inclusion criteria included paediatric patients aged 7 to 12 years with femur shaft fractures that were managed surgically. Exclusion criteria included patients whose case records lacked adequate follow-up information, patients with pathological fractures, and patients whose fractures were managed with methods other than antegrade stainless steel flexible intramedullary rods.

\section{Analysis of data}

Statistical analyses were performed using IBM SPSS version 25 (SPSS Inc., Chicago, IL, USA). T-tests were used to determine significance for continuous data and chi-square/Fisher's exact tests were used for categorical data. A p-value $<0.05$ was considered statistically significant. Pearson's correlation coefficient was 
Table I: Patient demographics, injury characteristics and management

\begin{tabular}{|c|c|c|c|c|c|c|c|c|c|}
\hline$\frac{\text { 름 }}{\frac{0}{2}}$ & 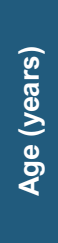 & 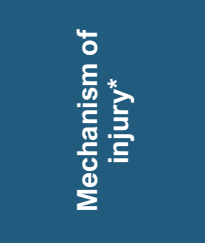 & 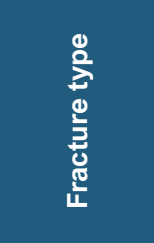 & 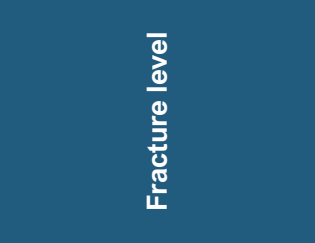 & 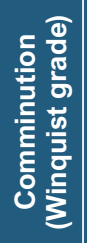 & 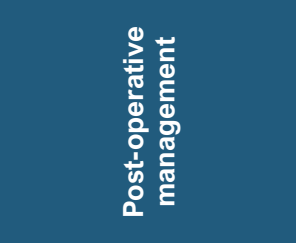 & 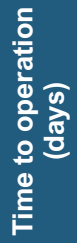 & 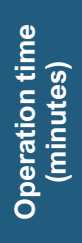 & 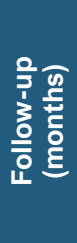 \\
\hline 1 & 7 & Fall & Transverse & Proximal third, mid third & 1 & Mobilisation & 4 & 80 & 15 \\
\hline 2 & 9 & Fall & Spiral & Subtrochanteric & 1 & Post-operative traction & 5 & 45 & 38 \\
\hline 3 & 8 & Gate fell on leg & Oblique & Proximal third, mid third & 1 & Mobilisation & 3 & 35 & 33 \\
\hline 4 & 7 & PVA & Transverse & Distal third & 1 & Mobilisation & 4 & 75 & 10 \\
\hline 5 & 11 & MVA & Transverse & Midshaft & 3 & Post-operative traction & 3 & 80 & 30 \\
\hline 6 & 7 & PVA & Transverse & Subtrochanteric & 2 & Mobilisation & 6 & 120 & 27 \\
\hline 7 & 11 & PVA & Transverse & Proximal third, mid third & 2 & Post-operative traction & 11 & 50 & 7 \\
\hline 8 & 8 & PVA & Transverse & Midshaft & 1 & Mobilisation & 3 & 55 & 21 \\
\hline 9 & 8 & PVA & Transverse & Proximal third, mid third & 1 & Post-operative traction & 8 & 50 & 15 \\
\hline 10 & 8 & Fall & Transverse & Midshaft & 1 & Mobilisation & 13 & 95 & 11 \\
\hline 11 & 9 & Fall & Oblique & Proximal third, mid third & 1 & Post-operative traction & 4 & 75 & 17 \\
\hline 12 & 11 & PVA & Transverse & Proximal third, mid third & 2 & Post-operative traction & 2 & 60 & 12 \\
\hline 13 & 12 & MVA & Spiral & Midshaft & 1 & Mobilisation & 5 & 35 & 11 \\
\hline 14 & 7 & MVA & Oblique & Proximal third, mid third & 1 & Mobilisation & 4 & 90 & 13 \\
\hline 15 & 10 & Fall & Oblique & Distal third & 1 & Post-operative traction & 1 & 45 & 12 \\
\hline 16 & 10 & Fall & Transverse & Midshaft & 1 & Mobilisation & 3 & 50 & 26 \\
\hline 17 & 9 & MVA & Transverse & Midshaft & 1 & Mobilisation & 10 & 45 & 10 \\
\hline 18 & 10 & Gate fell on leg & Spiral & Subtrochanteric & 3 & Post-operative traction & 6 & 65 & 18 \\
\hline 19 & 8 & Fall & Spiral & Subtrochanteric & 1 & Mobilisation & 3 & 80 & 27 \\
\hline 20 & 12 & Fall & Transverse & Midshaft & 1 & Mobilisation & 2 & 40 & 19 \\
\hline 21 & 9 & Fall & Transverse & Midshaft & 1 & Mobilisation & 2 & 110 & 15 \\
\hline 22 & 8 & PVA & Transverse & Proximal third, mid third & 2 & Mobilisation & 7 & 75 & 9 \\
\hline 23 & 9 & Fall & Transverse & Proximal third, mid third & 1 & Mobilisation & 3 & 50 & 18 \\
\hline
\end{tabular}

* MVA: motor vehicle accident; PVA: pedestrian vehicle accident

used to determine the correlation between fracture pattern and comminution with the Flynn outcome.

\section{Results}

Twenty-three children were selected for inclusion in the study from a total number of 67 who underwent surgery (Figure 4). The majority of patients were excluded due to lost files or inadequate notes (i.e. no AP pelvis X-ray) making analysis impossible due to lack of data. The patient demographics, injury characteristics and management are presented in Table $I$. The average age of the patients at the time of injury was 9 years (range: $7-12$ ). Three patients in the series had multiple injuries and were categorised as polytrauma. One patient had a Gustilo-Anderson grade II open fracture. One fracture required open reduction; although it went on to union, it developed late sepsis with sequestrum. The sepsis later resolved following sequestrectomy.

The average time to surgery was five days (range: 1-11). The average surgical time was 65 minutes (range: 35-120). The majority of patients (14) were mobilised immediately post-operatively on crutches, while the remainder required post-operative traction. The average time to removal of rods following surgery was 7.6 months (range: 3.2-36.3).

The average follow-up time of the patients was 17.9 months (range: 6.8-37.5). The patients' post-operative and radiological

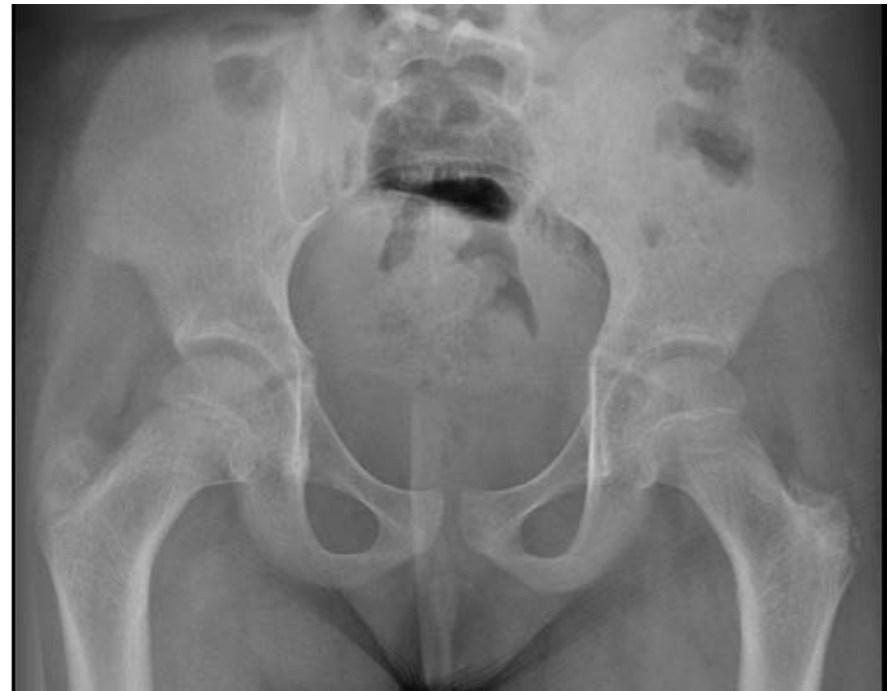

Figure 5. Evidence of epiphysiodesis of left greater trochanteric physis

findings are presented in Table II. Union was achieved in all patients. There was valgus malalignment in two patients of $11^{\circ}$ and $7^{\circ}$, and apex anterior angulation in one patient of $11^{\circ}$. Two patients had closure of their greater trochanteric epiphysis evident on 
Table II: Post-operative clinical and radiological findings

\begin{tabular}{|c|c|c|c|c|c|c|c|c|c|}
\hline $\begin{array}{l}\text { 릉 } \\
\text { 윰 }\end{array}$ & 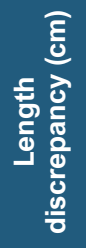 & $\frac{5}{\frac{5}{5}}$ & 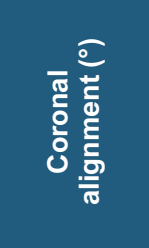 & 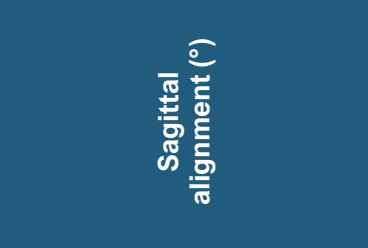 & 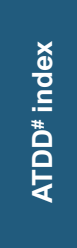 & 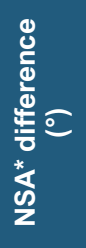 & $\begin{array}{l}\frac{0}{5} \\
\frac{0}{0} \\
\frac{d}{\Phi} \\
\delta \\
\Phi \\
\frac{\Phi}{0}\end{array}$ & 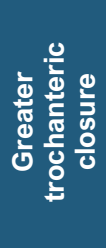 & 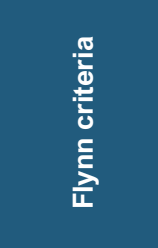 \\
\hline 1 & -0.5 & Yes & 0 & 0 & 1.88 & 6.5 & No & No & Excellent \\
\hline 2 & -1 & Yes & 0 & 0 & 1.29 & 5 & No & No & Excellent \\
\hline 3 & -1 & Yes & 0 & 0 & 0.90 & 6 & No & No & Excellent \\
\hline 4 & 1 & Yes & 0 & 0 & 0.96 & 0.5 & No & No & Excellent \\
\hline 5 & -1 & Yes & 0 & 0 & 1.00 & -3 & No & No & Poor \\
\hline 6 & -1 & Yes & $13^{\circ}$ valgus & 0 & 1.20 & 5.5 & No & No & Poor \\
\hline 7 & 0 & Yes & 0 & $11^{\circ}$ apex anterior angulation & 1.35 & 6.5 & No & No & Poor \\
\hline 8 & 0 & Yes & 0 & $4^{\circ}$ apex posterior angulation & 0.85 & -3 & No & No & Excellent \\
\hline 9 & -1.5 & Yes & 0 & 0 & 0.95 & -7 & No & No & Satisfactory \\
\hline 10 & 0.2 & Yes & 0 & 0 & 0.75 & -2 & No & No & Excellent \\
\hline 11 & -2 & Yes & 0 & 0 & 1.40 & 9 & No & Yes & Satisfactory \\
\hline 12 & 0 & Yes & 0 & 0 & 1.00 & -3 & No & No & Excellent \\
\hline 13 & 1.9 & Yes & 0 & $5^{\circ}$ apex posterior angulation & 1.00 & -4 & No & Yes & Satisfactory \\
\hline 14 & 1 & Yes & 0 & 0 & 0.95 & -7 & No & No & Excellent \\
\hline 15 & -1.5 & Yes & 0 & 0 & 1.00 & -0.4 & No & No & Satisfactory \\
\hline 16 & 0 & Yes & 0 & 0 & 1.08 & 3 & No & No & Excellent \\
\hline 17 & -0.8 & Yes & 0 & 0 & 0.90 & 0 & No & No & Excellent \\
\hline 18 & -0.2 & Yes & 0 & 0 & 0.91 & -6 & No & No & Excellent \\
\hline 19 & -0.6 & Yes & 0 & 0 & 1.43 & 11 & No & No & Excellent \\
\hline 20 & -1.5 & Yes & $7^{\circ}$ valgus & 0 & 1.30 & 4 & No & No & Satisfactory \\
\hline 21 & 0 & Yes & 0 & 0 & 1.12 & 5 & No & No & Excellent \\
\hline 22 & -0.3 & Yes & 0 & 0 & 0.96 & -5 & No & No & Excellent \\
\hline 23 & -0.5 & Yes & $5^{\circ}$ valgus & $3^{\circ}$ apex anterior angulation & 1.05 & 6 & No & No & Excellent \\
\hline
\end{tabular}

\# ATDD: articulo-trochanteric distance difference; * NSA: neck shaft angle

Table III: Flynn criteria ${ }^{6}$

\begin{tabular}{|l|c|c|c|}
\hline & Excellent & Satisfactory & \multicolumn{1}{|c|}{ Poor } \\
\hline Leg length discrepancy & $<1.0 \mathrm{~cm}$ & $<2.0 \mathrm{~cm}$ \\
\hline Malalignment & $<5^{\circ}$ & $<10^{\circ}$ \\
\hline Pain & None & None \\
\hline Complications & None & Present \\
\hline Results & $15(65 \%)$ & $5(22 \%)$ & Major/lasting morbidity \\
\hline
\end{tabular}

radiographs (Figure 5). The average ATDD index was 1.08 (range: $0.75-1.88$ ) in males and 1.14 (range: $0.95-1.40$ ) in females. The NSAD ranged from $-7^{\circ}$ to $11^{\circ}$. Osteonecrosis of the femoral head was not seen in any patients.

Flynn's criteria are shown in Table III. ${ }^{6}$ Of the three patients with poor results, two had pain, one of which also had malalignment $13^{\circ}$ of valgus and one patient had $11^{\circ}$ of apex anterior angulation. All patients had full range of movement of the knee. The leg length discrepancies ranged from $1.5 \mathrm{~cm}$ of shortening to $1.9 \mathrm{~cm}$ of lengthening. None of the patients had skin or prominent nail end complications.

The small sample size allowed for very limited statistical analysis. No statistically significant correlation was found between age and malalignment $(p=0.10)$. The proportion of patients with malalignment and with leg length discrepancies was statistically greater in children older than 11 years, with p-values of 0.031 and 0.005 , respectively. Comminution had a statistically significant association with malalignment $(p=0.02)$. Using Pearson's correlation, we found no statistically significant correlation between the fracture pattern $(p=0.74)$ or comminution $(p=0.66)$ and the Flynn outcome.

\section{Discussion}

The treatment of femoral shaft fractures in children lacks consensus in the literature. ${ }^{6}$ Traditionally the management of paediatric femur 
fractures involved a period of traction followed by hip spica cast immobilisation. ${ }^{7}$ There has, however, been a trend towards early operative management, especially in older children. The 2015 American Academy for Orthopaedic Surgeons (AAOS) evidencebased clinical practice guidelines for the treatment of paediatric diaphyseal femoral fractures provides a limited recommendation for the use of elastic intramedullary nails in children between the ages 5 to 11 years. $^{8}$ Conservative treatment inevitably resulted in prolonged immobilisation with negative effects on the child's social development, schooling and family. ${ }^{9-11}$ Increasing pressure on hospital beds lends impetus to management techniques that facilitate early mobilisation and discharge..$^{12}$

Operative options include external fixation, plating and flexible or rigid intramedullary nailing. ${ }^{7}$ Shemshaki et al. compared hip spica casting with FIN in children aged 6 to 12 years and found significant benefits with fewer complications with intramedullary nailing..$^{13}$ Bar-On et al. compared external fixation with FIN. They recommended the use of FIN as they found that there was more callus formation, as well as earlier return to full weight-bearing, full range of movement and return to school with FIN. ${ }^{14}$ Wani et al. reported similar results but recommended that the decision be left to the surgeon, as certain fractures, such as very distal or proximal fractures, may benefit from external fixation. ${ }^{15}$ Chen et al. found that the use of FIN was associated with a shorter operative time, less blood loss and shorter length of hospitalisation compared to submuscular plating. ${ }^{16}$

Concerns with antegrade nailing are that the blood supply to the femoral head may be compromised and that penetration through the greater trochanteric epiphysis may lead to epiphysiodesis and proximal femoral growth deformities. It is for these reasons that a retrograde approach, or antegrade approach with an entry port distal to the greater trochanteric epiphysis has been popularised with FIN insertion. ${ }^{17}$ However, some authors still consider an antegrade approach through the tip of the trochanter to be safe. ${ }^{18-20}$

The main blood supply to the femoral head is from the lateral ascending cervical artery in the piriformis fossa. ${ }^{21}$ Momberger et al. believed that entry through the greater trochanter completely avoided these vessels and would decrease the incidence of osteonecrosis. ${ }^{22}$ This was further supported by the research of Gordon et al., Townsend et al. and Elgohary et al. ${ }^{20,23,24}$ In their review of the literature MacNeil et al. found no evidence of osteonecrosis with a lateral greater trochanteric entry, a $1.4 \%$ rate of osteonecrosis with a tip of the greater trochanter entry and a $2 \%$ rate of osteonecrosis with a piriformis fossa entry point. ${ }^{25}$ In this study, radiographic follow-up showed no evidence of osteonecrosis. We attribute this to the small entry portal on the tip of the trochanter made with the $4.5 \mathrm{~mm}$ Rush rod awl, thus minimising the risk of damage to the blood supply.

Gage et al. and Herndon et al. believed that after the age of 8 years, trochanteric epiphysiodesis resulted in little or no deformity of the proximal femur, as growth was appositional. ${ }^{26,27}$ Raney et al. disagreed. They reviewed five patients who had changes to their proximal femur following epiphysiodesis secondary to reamed antegrade nailing. These changes were noted within five to eight months of the operation in four of the patients, and the fifth patient only showed changes after three years. Furthermore, they believed that active growth of the physis was present in the second decade and showed that there was very little space in the proximal femur to avoid the physis. They did, however, note that although there were significant radiological changes, none of the children had functional impairment. ${ }^{28}$ Gonzalez-Herranz et al. found significant changes to the proximal femur in patients older than 13 years who had antegrade nails inserted. They considered these iatrogenic changes to be pre-arthritic and recommended varus osteotomies in severe cases. ${ }^{5}$ Schofield et al. showed that epiphysiodesis of the greater trochanter resulted in a long valgus femoral neck. ${ }^{29}$
In contrast, Elgohary et al. and Gordon et al. reviewed 23 children aged 9 to 15 years, and 25 children aged 7 to 13 years, respectively, and found no proximal femur changes after reamed antegrade rigid intramedullary nails. ${ }^{20,23}$ Furthermore, Carey et al. reported no growth arrest following entry through the greater trochanteric epiphysis and, although there were changes with the ATD and neck shaft angle, neither were clinically significant. ${ }^{18}$ Galpin et al. who favoured an entry through the tip of the greater trochanter, further supported these findings. They also found no growth arrest of the greater trochanter and, therefore, suggested that a smooth unreamed nail does not affect the epiphysis. ${ }^{19}$ In this study two patients, aged 9 and 12 years, had radiographic evidence of greater trochanteric epiphysiodesis. Neither of these patients, however, had significant changes in their ATDD or neck shaft angle although they only achieved 'satisfactory' outcomes according to Flynn's clinical outcomes score. Both cases were noted to lose points due to leg length discrepancies, which was more likely related to the fracture characteristics (one a spiral and the other an oblique fracture) than damage to the greater trochanteric epiphysis. Two patients in this study did have morphological changes to the proximal femur. One patient had an increased ATDD index and another had an increased NSAD. Both however, had excellent outcomes according to Flynn's clinical outcomes score, suggesting that these changes were not clinically significant.

Without the ability to lock FIN, stability is one of the major concerns. ${ }^{30}$ Length stable fractures, such as transverse fractures, lend themselves to FIN. Comminuted, long spiral and long oblique fractures lack inherent axial stability and are considered length unstable fracture patterns. ${ }^{31}$ In two studies by Sink et al., FIN was recommended for stable fracture patterns whereas alternative treatment was advised for fixation of unstable fracture patterns. ${ }^{30,31}$ Alternatively, some researchers have recommended post-operative immobilisation for unstable fractures, although they were unable to substantiate this with statistically significant evidence.6,17,32 In contrast, in a mechanical study on simulated bones, Lee et al. found axial stiffness in comminuted fractures to be equivalent to transverse fractures with retrograde flexible nailing. ${ }^{33}$ Furthermore, Fricka et al. found that antegrade flexible nailing may have a greater resistance to shortening than retrograde flexible nailing. ${ }^{34}$ None of the patients in this study had leg length discrepancies greater than $2 \mathrm{~cm}$, with the majority (20) being less than $1 \mathrm{~cm}$ short. Five patients in this study achieved a 'satisfactory' outcome, according to Flynn's criteria, due to a limb length discrepancy of $1-2 \mathrm{~cm}$. One patient had $7^{\circ}$ of valgus malalignment. Statistical analysis of the data showed no correlation between fracture pattern and leg length discrepancy.

Moroz et al. showed that children older than 11 years or with bodyweight greater than $49 \mathrm{~kg}$ had an increased complication rate, including angular deformity. ${ }^{35}$ Sink et al. made similar conclusions and suggested children over the age of 11 years should not be stabilised with flexible nails. ${ }^{30}$ Heinrich et al. however, found no significant differences in angular deformities when comparing children in the age groups of 6 to 9 years and older than 10 years. ${ }^{36}$ In this study children older than 11 years had a greater proportion of malalignment and leg length discrepancies than those younger than 11. Mehlmann et al., in their mechanical study, showed that retrograde nailing was superior to antegrade nailing with regard to bending stiffness in distal third fractures of the femur. ${ }^{37}$ Due to its higher modulus of elasticity and a larger elastic limit, stainless nails are less flexible than their titanium counterparts. Flexibility, however, is also related to the diameter of the nail, and stainless steel nails up to a diameter of $4 \mathrm{~mm}$ have been considered flexible in previous studies. ${ }^{38}$ Hence the $3.2 \mathrm{~mm}$ nails used in this study may be considered flexible. Wall et al. compared stainless steel versus titanium nails and reported a higher incidence of malunion 
in the titanium group. ${ }^{38}$ In children aged 6 to 10 years, $10^{\circ}$ of coronal and $15^{\circ}$ of sagittal angulation is acceptable and this decreases to $5^{\circ}$ and $10^{\circ}$ respectively in children older than 11 years. ${ }^{39}$ In this study, three patients (13\%) had angular deformities not within these limits, which is similar to the malalignment reported in the reviewed literature, which ranged from $8 \%$ to $18 \% .6,18,19,32,35,36,40$

To facilitate removal, retrograde flexible nails are deliberately left protruding from the bone entry portal and hence have a tendency to cause problems. Luhmann et al. found the most significant problem they encountered with retrograde nails was pain and skin erosion from prominence of the nail at the insertion site. ${ }^{32}$ Nail prominence may also result in knee pain and reduced range of movement. Similar complications were found by other authors with rates ranging from $4.8 \%$ to $93 \%$ of patients, with the large range presumably due to varying length of the nail that was left prominent. $6,30,31,35,38 \mathrm{~A}$ balance is required between cutting the nail short enough to avoid irritation and maintaining it long enough to aid removal and prevent slippage of the nail into the canal, which may compromise stability. Luhmann et al. recommended the nail is trimmed and then impacted, leaving less than $2.5 \mathrm{~cm}$ of the nail protruding. ${ }^{32}$ In this study the nails were deliberately left protruding approximately $2 \mathrm{~cm}$ from the greater trochanter to aid with later removal. Skin complications or complaints regarding nail prominence were not seen in this study.

This study has a number of limitations. These include the retrospective nature of the study and the small sample size allowed for very limited statistical analysis and underpowered results. Further limitations include the relatively short follow-up (mean of 18 months and the longest of 3.1 years) with regard to screening for osteonecrosis, as well as the morphological changes within the proximal femur. Ideally these patients should be followed up longer to determine if osteonecrosis develops and if the changes to the proximal femur manifest in clinical problems.

\section{Conclusion}

Antegrade nailing using the described technique of a small entry portal through the tip of the greater trochanter does not appear to place the blood supply to the femoral head at risk or increase the risk of clinically significant morphological changes to the proximal femur. The follow-up, however, was relatively short and further follow-up is required. In this study 20 out of 23 patients achieved an excellent or satisfactory outcome according to Flynn's criteria with all fractures uniting and malalignment rates similar to the rates achieved in the reviewed literature. Furthermore, antegrade insertion avoids the skin and prominent nail complications seen with retrograde insertion. The relatively low cost of this technique is useful in South Africa with its high trauma burden and resource limitations in the public sector.

\section{Ethics statement}

Ethical approval was obtained from the University of KwaZulu-Natal BREC Ethics Committee (BE392/16), the KwaZulu-Natal Department of Health (KZ_2016RP46_898) and the Ngwelezana Hospital CEO prior to the commencement of data collection. All participant names, information and relevant data were kept confidential. Patients were assigned a number to keep their identities confidential on the data sheets and database.

\section{Declarations}

The authors declare authorship of this article and that they have followed sound scientific research practice. This research is original and does not transgress plagiarism policies.

\section{Acknowledgments}

I would like to thank Matthew Foster and Maureen Zungu for assisting me with data collection.

\section{Author contributions}

RCR: Literature review, data collection, primary author and data interpretation and analysis

MNR: Paper editing and supervision

SW: Statistical analysis

PDR: Idea conception, paper editing, supervision and data collection

\section{ORCID}

RC Rosin (D) http://orcid.org/0000-0002-6247-4039 MN Rasool (iD http://orcid.org/0000-0002-2073-8358 W Sibanda (1) http://orcid.org/0000-0001-5702-2436 PD Rollinson (D) http://orcid.org/0000-0002-2384-7250

\section{References}

1. Mughal MA, Dix-Peek SI, Hoffman EB. The epidemiology of femur shaft fractures in children. SA Orthop J. 2013;12(4):23-27.

2. John R, Sharma S, Raj GN, Singh J, CV, Rhh A, et al. Current concepts in paediatric femoral shaft fractures. Open Orthop J. 2017;11:353-68.

3. Winquist RA, Hansen ST, Jr. Comminuted fractures of the femoral shaft treated by intramedullary nailing. Orthop Clin North Am. 1980;11(3):633-48.

4. Langenskiold A, Salenius P. Epiphysiodesis of the greater trochanter. Acta Orthop Scand. 1967;38(2):199-219.

5. Gonzalez-Herranz P, Burgos-Flores J, Rapariz JM, Lopez-Mondejar JA, Ocete JG, Amaya S. Intramedullary nailing of the femur in children. Effects on its proximal end. $J$ Bone Joint Surg Br. 1995;77(2):262-66.

6. Flynn JM, Hresko T, Reynolds RA, Blasier RD, Davidson R, Kasser J. Titanium elastic nails for pediatric femur fractures: a multicenter study of early results with analysis of complications. $J$ Pediatr Orthop. 2001;21(1):4-8.

7. Anglen JO, Choi L. Treatment options in pediatric femoral shaft fractures. J Orthop Trauma. 2005;19(10):724-33.

8. Jevsevar DS, Shea KG, Murray JN, Sevarino KS. AAOS clinical practice guideline on the treatment of pediatric diaphyseal femur fractures. J Am Acad Orthop Surg. 2015;23(12):e101.

9. Hughes BF, Sponseller PD, Thompson JD. Pediatric femur fractures: effects of spica cast treatment on family and community. J Pediatr Orthop. 1995;15(4):457-60.

10. Hunter JB. Femoral shaft fractures in children. Injury. 2005;36 Suppl 1:A86-93.

11. Reeves RB, Ballard RI, Hughes JL. Internal fixation versus traction and casting of adolescent femoral shaft fractures. J Pediatr Orthop. 1990;10(5):592-95.

12. Barry M, Paterson JM. A flexible intramedullary nails for fractures in children. J Bone Joint Surg Br. 2004;86(7):947-53.

13. Shemshaki HR, Mousavi H, Salehi G, Eshaghi MA. Titanium elastic nailing versus hip spica cast in treatment of femoral-shaft fractures in children. J Orthop Traumatol. 2011;12(1):45-48.

14. Bar-On E, Sagiv S, Porat S. External fixation or flexible intramedullary nailing for femoral shaft fractures in children. A prospective, randomised study. J Bone Joint Surg Br. 1997;79(6):975-78.

15. Wani MM, Rashid M, Dar RA, Bashir A, Sultan A, Wani I, et al. Use of external fixator versus flexible intramedullary nailing in closed pediatric femur fractures: comparing results using data from two cohort studies. Eur J Orthop Surg Traumatol. 2016;26(2):223-30.

16. Chen LK, Sullivan BT, Sponseller PD. Submuscular plates versus flexible nails in preadolescent diaphyseal femur fractures. $J$ Child Orthop. 2018;12(5):488-92.

17. Heinrich SD, Drvaric D, Darr K, MacEwen GD. Stabilization of pediatric diaphyseal femur fractures with flexible intramedullary nails (a technique paper). J Orthop Trauma. 1992;6(4):452-59.

18. Carey TP, Galpin RD. Flexible intramedullary nail fixation of pediatric femoral fractures. Clin Orthop Relat Res. 1996(332):110-18

19. Galpin RD, Willis RB, Sabano N. Intramedullary nailing of pediatric femoral fractures. J Pediatr Orthop. 1994;14(2):184-89.

20. Elgohary HS, El Adl WA. Antegrade rigid nailing through the tip of the greater trochanter for pediatric femoral shaft fractures. Eur $J$ Orthop Surg Traumatol. 2014;24(7):1229-35. 
21. Chung SM. The arterial supply of the developing proximal end of the human femur. J Bone Joint Surg Am. 1976;58(7):961-70.

22. Momberger N, Stevens P, Smith J, Santora S, Scott S, Anderson J. Intramedullary nailing of femoral fractures in adolescents. J Pediatr Orthop. 2000;20(4):482-84.

23. Gordon JE, Swenning TA, Burd TA, Szymanski DA, Schoenecker PL. Proximal femoral radiographic changes after lateral transtrochanteric intramedullary nail placement in children. $J$ Bone Joint Surg Am. 2003;85-A(7):1295-301.

24. Townsend DR, Hoffinger S. Intramedullary nailing of femoral shaft fractures in children via the trochanter tip. Clin Orthop Relat Res. 2000(376):113-18.

25. MacNeil JA, Francis A, El-Hawary R. A systematic review of rigid, locked, intramedullary nail insertion sites and avascular necrosis of the femoral head in the skeletally immature. $J$ Pediatr Orthop. 2011;31(4):377-80.

26. Gage JR, Cary JM. The effects of trochanteric epiphyseodesis on growth of the proximal end of the femur following necrosis of the capital femoral epiphysis. J Bone Joint Surg Am. 1980;62(5):785-94.

27. Herndon WA, Mahnken RF, Yngve DA, Sullivan JA. Management of femoral shaft fractures in the adolescent. $J$ Pediatr Orthop. 1989;9(1):29-32.

28. Raney EM, Ogden JA, Grogan DP. Premature greater trochanteric epiphysiodesis secondary to intramedullary femoral rodding. $J$ Pediatr Orthop. 1993;13(4):516-20.

29. Schofield CB, Smibert JG. Trochanteric growth disturbance after upper femoral osteotomy for congenital dislocation of the hip. $J$ Bone Joint Surg Br. 1990;72(1):32-36.

30. Sink EL, Faro F, Polousky J, Flynn K, Gralla J. Decreased complications of pediatric femur fractures with a change in management. J Pediatr Orthop. 2010;30(7):633-37.

31. Sink EL, Gralla J, Repine M. Complications of pediatric femur fractures treated with titanium elastic nails: a comparison of fracture types. J Pediatr Orthop. 2005;25(5):577-80.

32. Luhmann SJ, Schootman M, Schoenecker PL, Dobbs MB, Gordon JE. Complications of titanium elastic nails for pediatric femoral shaft fractures. J Pediatr Orthop. 2003;23(4):443-47.

33. Lee SS, Mahar AT, Newton PO. Ender nail fixation of pediatric femur fractures: a biomechanical analysis. J Pediatr Orthop. 2001;21(4):442-45.

34. Fricka KB, Mahar AT, Lee SS, Newton PO. Biomechanical analysis of antegrade and retrograde flexible intramedullary nail fixation of pediatric femoral fractures using a synthetic bone model. J Pediatr Orthop. 2004;24(2):167-71.

35. Moroz LA, Launay F, Kocher MS, Newton PO, Frick SL, Sponseller $\mathrm{PD}$, et al. Titanium elastic nailing of fractures of the femur in children. Predictors of complications and poor outcome. $J$ Bone Joint Surg Br. 2006;88(10):1361-66.

36. Heinrich SD, Drvaric DM, Darr K, MacEwen GD. The operative stabilization of pediatric diaphyseal femur fractures with flexible intramedullary nails: a prospective analysis. J Pediatr Orthop. 1994;14(4):501-507.

37. MehIman CT, Nemeth NM, Glos DL. Antegrade versus retrograde titanium elastic nail fixation of pediatric distal-third femoral-shaft fractures: a mechanical study. J Orthop Trauma. 2006;20(9):608-12.

38. Wall EJ, Jain V, Vora V, Mehlman CT, Crawford AH. Complications of titanium and stainless steel elastic nail fixation of pediatric femoral fractures. J Bone Joint Surg Am. 2008;90(6):1305-13.

39. Wilkins KE. Principles of fracture remodeling in children. Injury. 2005;36 Suppl 1:A3-11.

40. Ligier JN, Metaizeau JP, Prevot J, Lascombes P. Elastic stable intramedullary nailing of femoral shaft fractures in children. $J$ Bone Joint Surg Br. 1988;70(1):74-77. 